\title{
Reflexões foucaultianas sobre o racismo enquanto estratégia de governo de si e dos outros no episódio da "tia do café"
} Foucaultian reflections about racism as a strategy of governing itself and others in the episode of "the coffee aunt"

\author{
Marluce Pereira da Silva \\ Professora Associada IV da Universidade Federal da Paraíba, Brasil. Doutora em Linguística e Língua Portuguesa pela \\ Universidade Estadual Paulista Júlio de Mesquita Filho - UNESP, Araraquara, Brasil. E-mail: marlucepereira@uol.com.br \\ Cid Augusto Escossia Rosado \\ Docente na Sociedade Educacional Mater Christi e na Universidade do Estado do Rio Grande do Norte. Doutorando em Estudos \\ da Linguagem pela Universidade Federal do Rio Grande do Norte (UFRN), Brasil. E-mail: cidaugusto@gmail.com
}

\section{Resumo:}

As redes sociais são palco frequente de eventos discriminatórios, a exemplo da polêmica entre o humorista Danilo Gentili e a senadora Regina Sousa (PT-PI), em 2016. O episódio "tia do café" inspirou este artigo que problematiza o racismo como estratégia de poder relacionada ao governo de si e dos outros. Para tanto, serve-se da pesquisa bibliográfica focada nos estudos sobre racismo, governamentalidade e parresía de Foucault $(2004 ; 2005 ; 2007 ; 2011 ; 2013 ; 2014)$ e na teoria social de Fanon (2008), bem como do estudo de caso; e conclui, ao abordar a linguagem como prática social, que o racismo é uma construção sócio-histórica originadora de subjetividades que se manifestam consciente e inconscientemente da fala dos sujeitos.

\section{Palavras-chave:}

Racismo; Governo de si e dos outros; Subjetivação; Parresía.

\begin{abstract}
:
Social networks are often favorite place to show off discriminatory events, such as the polemic episode held between humorist Danilo Gentili and Senator Regina Sousa (PTPI), in 2016. The episode "the coffee aunt" inspired this article that problematizes racism as a power strategy to govern itself and others. Therefore, it will be used the bibliographic research focused on the studies of governmentality and parrhesia by Foucault $(2004,2005,2007,2011,2013,2014)$, and social theory by Fanon (2008), as well the case study. The conclusion, it is that, while approaching language as social practice, racism is a socio-historical construction that originates subjectivities that are consciously and unconsciously manifested by ones speech.
\end{abstract}

\section{Keywords:}

Racism; Government of itself and others; Subjectivation; Parrhesia. 


\section{Introdução}

O racismo é um fenômeno de raízes remotas e proporções globais que tem afetado as relações internas e externas dos povos, ao longo da história. Sua concepção mais próxima do senso comum é a de hierarquização do ser humano pela cor da pele, paradigma esse, que, além de práticas discriminatórias, origina subjetivações e formas de governança de si e dos outros.

O racismo tem várias faces. No Brasil, por herança da escravatura, que perdurou do século XVI ao final do século XIX, a mais exposta é a que atinge a população negra. E, não obstante o art. $5^{\circ}$, XLII, da Constituição Federal dizer que "a prática do racismo constitui crime inafiançável e imprescritível, sujeito à pena de reclusão, nos termos da lei”, são frequentes os eventos reveladores dessa conduta.

O noticiário está repleto de episódios protagonizados por indivíduos em diferentes espaços, principalmente em estádios de futebol. Em outros cenários - e também com a utilização da mídia -, registrou-se a expressão de discursividades com sentidos de práticas racistas, como no caso que envolveu o comediante Danilo Gentili e a senadora negra Regina Sousa (PT/PI), num momento de grandes embates políticos.

Tratava-se do impeachment da presidente Dilma Roussef. Todos os passos do processo, de 2 de dezembro de 2015 a 31 de agosto de 2016, foram transmitidos ao vivo, a partir dos canais televisivos, radiofônicos e de Internet da Câmara dos Deputados e do Senado, além dos veículos comerciais. Por isso, o brasileiro teve a chance de acompanhar os fatos em tempo real e de opinar, especialmente nas redes sociais.

Assim, aos 11 de maio de 2016, enquanto Regina Sousa ocupava a tribuna do Senado em defesa da correligionária, Gentili, âncora do Programa "The Noite", do SBT, publicou no Twitter: "Senadora? Achei que fosse a tia do café". Regina Sousa voltou à tribuna, na sessão seguinte, para acusar Gentili por racismo e se autoafirmar negra, do "cabelo pixaim", além de anunciar processo contra o humorista.

Não é a primeira vez que o comediante é acusado de discriminar negros. Em 2009, ele escreveu "King Kong, um macaco que, depois que vai para a cidade e fica famoso, pega uma loira. Quem ele acha que é? Jogador de futebol?”. Já em $1^{\circ}$ de outubro de 2012, reagiu assim a um internauta que o classificou de racista: "Sério

INTERIN, v. 24, n. 2, jul./dez. 2019. ISSN: 1980-5276.

Marluce Pereira da Silva; Cid Augusto Escossia Rosado. Reflexões foucaultianas sobre o racismo enquanto estratégia de governo de si e dos outros no episódio da "tia do café"..p. 103-118. DOI 10.35168/1980-5276.UTP.interin.2019.Vol24.N2.pp103-118 
@ Lasombra Ribeiro vamos esquecer isso... Quantas bananas vc quer pra deixar essa história pra lá?”.

Diante desse quadro, problematizando o comentário de Gentili e a reação da senadora aos dizeres do apresentador, propõe-se, neste artigo, a análise de práticas discursivas que perpassam as falas de ambos e que expressam efeitos de sentidos acerca das maneiras de se relacionar consigo mesmo - ou do governo de si face ao pertencimento racial.

O trabalho serve-se, inicialmente, do método bibliográfico de pesquisa para construção do referencial teórico necessário a reflexões acerca do racismo enquanto estratégia de governo de si e dos outros, envolvendo obras de Foucault (2004; 2005; 2007; 2011; 2013; 2014) e Fanon (2008). No segundo momento, à luz desses autores, inserindo-se entre os estudos que buscam entender as práticas da linguagem na constituição de práticas sociais, passa-se ao estudo de caso dos enunciados produzidos no embate entre Danilo Gentili e Regina Sousa.

O percurso analítico do corpus formado por uma publicação do humorista no Twitter e da resposta da senadora na tribuna do Senado abrangerá, em primeiro plano, os três eixos da parresía (dizer tudo, dizer-a-verdade e a fala franca) e o risco assumido pelos interlocutores. Embora Foucault (2010) afaste a estrutura interna e o objetivo do discurso na investigação sobre a parresía, tais aspectos serão considerados em segundo plano, pois ajudam a desvendar a gênese da "Tia do Café".

$\mathrm{O}$ texto está dividido em três seções. Na primeira, apresenta-se o suporte teórico da análise. Na segunda, são problematizados modos de subjetivação que atravessam os dizeres de Regina Sousa e Danilo Gentili. E, ao final, apresentam-se as conclusões apreendidas do percurso analítico, de que o racismo é uma construção sócio-histórica originadora de subjetividades que se manifestam consciente e inconscientemente na linguagem.

\section{Governamentalidade, racismo e parresía}

Foucault (2007) usou a expressão "governamentalidade" para designar inicialmente três coisas: exercício institucional do poder sobre a população; aceitação

INTERIN, v. 24, n. 2, jul./dez. 2019. ISSN: 1980-5276. 
desse governo, com seus aparelhos e saberes, por outras instâncias de governo; e a passagem do Estado de Justiça para o estado administrativo. Nas palavras dele:

O que pretendo fazer nestes próximos anos é uma história da governamentalidade. E com esta palavra quero dizer três coisas:

1 - o conjunto constituído pelas instituições, procedimentos, análises e reflexões, cálculos e táticas que permitem exercer esta forma bastante específica e complexa de poder, que tem por alvo a população, por forma principal de saber a economia política e por instrumentos técnicos essenciais os dispositivos de segurança.

2 - a tendência que em todo o Ocidente conduziu incessantemente, durante muito tempo, à preeminência deste tipo de poder, que se pode chamar de governo, sobre todos os outros - soberania, disciplina, etc. - e levou ao desenvolvimento de uma série de aparelhos específicos de governo e de um conjunto de saberes.

3 - resultado do processo através do qual o Estado de justiça da Idade Média, que se tornou nos séculos XV e XVI Estado administrativo, foi pouco a pouco governamentalizado (FOUCAULT, 2007, p. 291).

Os três pontos remetem, no desdobramento da temática, à elaboração de um conceito de população, cuja vida política é gerida por um governo central, bem como ao entendimento de que os indivíduos desse conjunto se utilizam, na família e demais instituições, de estratégias para governar a si e aos outros.

"Governamentalidade" seria, portanto, o "contato entre as tecnologias de dominação sobre os outros e as tecnologias de si” (FOUCAULT, 2004, p. 324); enquanto governo abrange as "técnicas e procedimentos destinados a dirigir a conduta dos homens", seja a própria ou a do próximo.

Dessa maneira, existiriam instâncias de governo, a começar do governo enquanto ente político centrado na relação entre o governante (presidente, rei, príncipe, soberano) e a população, com o emprego de técnicas e aparelhos de Estado de controle das liberdades individuais, na perspectiva da realização dos seus fins.

No interior dessa esfera, existiria o governo de segmentos organizados da sociedade, a exemplo da família, das igrejas, dos sindicatos. Na base, emerge o governo de si como instância moral que influencia a forma de o indivíduo circular nas outras esferas, aceitando ou rechaçando o poder que delas emana.

[...] os governantes, as pessoas que governam, a prática de governo são, por um lado, práticas múltiplas, na medida em que muita gente pode governar: o pai de família, o superior do convento, o pedagogo e o professor em relação à criança e ao discípulo. Existem, portanto, muitos governos, em relação aos quais o do príncipe governando seu Estado é apenas uma

INTERIN, v. 24, n. 2, jul./dez. 2019. ISSN: 1980-5276.

Marluce Pereira da Silva; Cid Augusto Escossia Rosado. Reflexões foucaultianas sobre o racismo enquanto estratégia de governo de si e dos outros no episódio da "tia do café"..p. 103-118. DOI 10.35168/1980-5276.UTP.interin.2019.Vol24.N2.pp103-118 
modalidade. Por outro lado, todos esses governos estão dentro do Estado ou da sociedade (FOUCAULT, 2007, p. 280).

O racismo, nas práticas múltiplas de governança, não é apenas a crença numa estirpe superior ou o preconceito contra pessoas de etnias diferentes. É também o conjunto de práticas e técnicas de governo de si e dos outros historicamente inspiradas no discurso da luta de raças e depois no discurso racista de cunho biológico.

É bem verdade, Foucault não aborda o segregacionismo enquanto técnica de governabilidade ou, pelo menos, não o faz explicitamente, mas abre caminho para essa interpretação ao enfatizar as múltiplas formas de governo como instâncias de poder e o conflito binário de grupos que articula um único corpo social.

A guerra de raças remete a "diferenças étnicas, diferenças das línguas; diferenças de força, de vigor, de energia e de violência, diferenças de selvageria e de barbárie, conquista e servidão de uma raça por uma outra" (FOUCAULT, 2005, p. 71); enquanto o racismo é a mesma batalha, mas na visão biológica.

Embora regido pelo governo político e fragmentado em núcleos de governamentalidade de si e dos outros, o corpo social composto por indivíduos de mesma nacionalidade torna-se, na perspectiva do racismo impulsionado pelo biopoder, uma "sociedade binária, dividida entre duas raças" (FOUCAULT, 2005, p. 94).

A ideia da pureza da raça, com tudo o que comporta a um só tempo de monístico, de estatal e de biológico, será aquela que vai substituir a ideia de luta de raças.

Quando o tema da pureza da raça toma o lugar da luta das raças, eu acho que nasce o racismo, ou que está se operando a conversão da contra-história em um racismo biológico (FOUCAULT, 2005, p. 95).

Determinados Estados incorporam a questão do racismo como elemento de governo. A Alemanha nazista, tomada como amostra, apresentava entre suas plataformas a proteção da pureza dos arianos em detrimento dos judeus, não importando se eram judeus alemães ou de origens nacionais diversas.

O velho antissemitismo do tipo religioso foi neutralizado num racismo de Estado somente no século XIX, a partir do momento que se constitui um racismo de Estado, no momento em que o Estado teve de aparecer, de funcionar e de se mostrar como o que assegura a integridade e a pureza da raça, contra a raça ou as raças que o infiltram, que introduzem em seu corpo elementos nocivos e que é preciso, consequentemente, expulsar por razões que são de ordem política e biológica ao mesmo tempo (FOUCAULT, 2005, p. 101).

INTERIN, v. 24, n. 2, jul./dez. 2019. ISSN: 1980-5276. 
Essa ideia do racismo enquanto técnica de governo de si e dos outros, centrada no exercício do poder, na conquista e na servidão, é compartilhada por Fanon (2008). Segundo ele, os "colonizadores" tendem a extirpar a cultura dos "colonizados", como forma de inferiorizá-los e dominá-los.

No tocante à guerra de raças, essa dominação dar-se-ia especialmente pela linguagem imposta pelo colonizador branco ao colonizado negro. Na perspectiva de Fanon (2008, p. 34), "quanto mais assimilar os valores culturais da metrópole, mais o colonizado escapará da sua selva. Quanto mais ele rejeitar sua negridão, seu mato, mais branco será".

Mas "o racismo colonial", invenção dos europeus, "não difere dos outros racismos", assegura Fanon (2008, p. 87). A guerra de raças ou o biorracismo têm no fundo a mesma perspectiva de exploração do homem pelo homem na engrenagem do poder, das lutas sociais e das forças econômicas.

No Brasil, a questão abrange ambos os momentos: a luta de raças, com a conquista e servidão africana, do século XVI ao XIX; e o racismo, da Lei Áurea (13 de maio de 1888) até hoje, com toda carga de preconceitos, segregações e dificuldade de acesso a direitos básicos por parcela significativa da população fundados na cor da pele.

O desenho foucaultiano do biopoder remete à falsa ideia de que a espécie humana comporta uma hierarquia estabelecida pela cor da pele, em que determinada raça, dita "pura" e "superior", nasce com o direito natural de governar as outras gentes, inclusive com direitos sobre vida e morte.

Com efeito, que é o racismo? É, primeiro, o meio de introduzir afinal, nesse domínio da vida de que o poder se incumbiu, um corte: o corte entre o que deve viver e o que deve morrer. No contínuo biológico da espécie humana, o aparecimento das raças, a distinção das raças, a hierarquia das raças, a qualificação de certas raças como boas e de outras, ao contrário, como inferiores, tudo isso vai ser uma maneira de fragmentar esse campo do biológico de que o poder se incumbiu; uma maneira de defasar, no interior da população uns grupos em relação aos outros. Em resumo, de estabelecer uma cesura que será do tipo biológico no interior de um domínio considerado como sendo precisamente um domínio biológico. Isso vai permitir ao poder tratar uma população como uma mistura de raças ou, mais exatamente, tratar a espécie, subdividir a espécie de que ele se incumbiu em subgrupos que serão, precisamente, raças. Essa é a primeira função do racismo: fragmentar, fazer cesuras no interior desse contínuo biológico a que se dirige o biopoder (FOUCAULT, 2005, p. 304-305).

INTERIN, v. 24, n. 2, jul./dez. 2019. ISSN: 1980-5276. 
Mas, o que tudo isso tem a ver com Parresía? Parresía, como se sabe, é dizer tudo, dizer-a-verdade e a fala franca. E, se a produção discursiva nesses três eixos é uma manifestação de poder, um exercício de governamentalidade, não há como negar sua interferência da produção de sentidos nas práticas racistas.

"Dizer tudo" tem o sentido literal de expressão, sem medo, sem amarras ideológicas, éticas, morais; "dizer-a-verdade" remete à crença pessoal do indivíduo no que está sendo dito; enquanto a "fala-franca" traduz-se em espontaneidade, em sinceridade.

Tais noções não se confundem, de acordo com Foucault (2010), com estratégias expositivas, retóricas, de ensino e nem de debate. Refletem, na realidade, uma técnica de relação de governo do sujeito consigo e com os outros que se manifesta de três maneiras: o dizer-a-verdade do oráculo, da confissão e do discurso político.

A verdade oracular, sabendo-se que a figura mitológica do oráculo revela as coisas e os sentidos dessas por meio de enigmas, é ambígua, pode ou não ser compreendida ou interpretada de maneiras contraditórias, a exemplo do que ocorre quando grupos cristãos de orientações distintas se debruçam sobre o mesmo trecho da bíblia, que é um oráculo, e dele tiram interpretações opostas.

A verdade confessional, em se tratando de parresía, é a coragem de enfrentar as consequências pela confissão dos erros. $\mathrm{O}$ fiel que se confessa ao padre na certeza da penitência, o delinquente que confessa seus crimes às autoridades, consciente da punição e a pessoa pública (políticos, artistas, escritores, jornalistas) que assumem erros ou posturas diante da opinião pública.

O dizer-a-verdade do discurso político é o que que mais se aproxima do governo de si e dos outros, com meias verdades - ou meias mentiras - que se articulam para justificar medidas, posições, mudanças de rumo, reações. E, embora a parresía na perspectiva foucaultiana não se confunda com o exercício do poder, o dizer-a-verdade do discurso político envolve relações de dominação e de poder.

Percebe-se ainda entre as preocupações de Foucault (2013, p. 42), identificar “como o dizer-a-verdade, a obrigação e a possibilidade de dizer a verdade nos procedimentos de governo podem mostrar de que modo o indivíduo se constitui como sujeito na relação consigo e na relação com os outros".

INTERIN, v. 24, n. 2, jul./dez. 2019. ISSN: 1980-5276.

Marluce Pereira da Silva; Cid Augusto Escossia Rosado. Reflexões foucaultianas sobre o racismo enquanto estratégia de governo de si e dos outros no episódio da "tia do café"..p. 103-118. DOI 10.35168/1980-5276.UTP.interin.2019.Vol24.N2.pp103-118 
A condição especial da parresía foucaultiana realiza-se, entretanto, quando a enunciação se materializa "em condições tais que o fato de dizer a verdade, e o fato de tê-la dito, vai ou pode ou deve acarretar consequências custosas para os que disseram a verdade" (FOUCAULT, 2013, p. 53).

$\mathrm{Na}$ perspectiva do risco pessoal, tanto o discurso racista quanto o antirracista pode ser parresiasta, à medida que os dois lados disputam o domínio da verdade num terreno propício a reações de ódio e violência, com a utilização de técnicas e estratégias de governança de si e dos outros.

Quando alguém diz tudo e assume francamente ódio a pessoas de determinada raça, cor, etnia, religião ou procedência nacional, coloca-se em risco pelo que acredita ser verdade e externa aspectos de governamentalidade, do que imagina de si e de seu "direito de ascendência" sobre os que julga inferiores.

Declarar-se pertencente a um grupo alvo de preconceitos exige do indivíduo a mesma coragem-da-verdade, às vezes ainda mais, e também é uma técnica de governo de si e dos outros, ao passo que rechaça o controle, contesta a superioridade e se posta como senhor dos próprios atos e governante do próprio destino.

Todo movimento de governamentalidade, de governo de si, de governo dos outros, de parresía, ganha forma na linguagem, através da linguagem. Por isso, o discurso racista ou antirracista objetificado neste artigo é historicamente constituído nas relações sociais e consolidado ou transformado ao longo do tempo.

Ressalta-se que o "fenômeno da linguagem", de acordo com Fanon (2008, p. 33), é de "importância fundamental" para se compreender o negro em relação ao “outro", o negro em relação ao negro e o negro em relação ao branco, pois é pela fala que se "assume uma cultura", que se suporta "o peso de uma civilização".

A linguagem, por assim dizer, promove a constituição de subjetividades por meio de mecanismos discursivos e sua análise possibilita, como busca Fanon (2008, p. 104), "compreender o ser do negro" nas sociedades marcadas por práticas discriminatórias, num cenário em que "o negro não tem mais de ser negro, mas sê-lo diante do branco", nas confluências e nos embates.

$\mathrm{O}$ que se tem hoje por racismo são, portanto, fragmentos de historicidades absorvidos pela ordem do discurso vigente, contemporânea, que certamente sofrerá 
modificações ao sabor das convergências e conflitos sociais, e com maior velocidade e campos de influência, dada a evolução dos meios de comunicação social.

As expressões de racismo que se analisa aqui, por exemplo, são frutos de uma realidade marcada por esses meios. Danilo Gentili usou uma rede social, o Twitter, onde arrebanha milhões de seguidores, enquanto Regina Sousa, a tribuna do Senado, com transmissão multimídia ao vivo (rádio, TV e Internet).

\section{3 "Senadora? achei que fosse a tia do café"}

Danilo Gentili pode não ser ou não se perceber racista, mas ao produzir o enunciado "Senadora? Achei que fosse a tia do café", permite-nos entender que há racismo no seu dizer. A sentença, a propósito, não é individual, pois ecoa um discurso social e historicamente constituído de que os indivíduos estão categorizados por elementos como idade, gênero, cor, origem.

Fig. 1 - imagem do Twitter de Gentili

Danilo Gentili 0

oDaniloGientil

Seguir

Senadora? Achei que fosse a tia do café RT

@Link_jr87: @DaniloGentili vc consegue

entender o que a Sen. Regina Sousa está

falando?

10.40 - 11 de mai de 2016

Fonte: imagem capturada no Twitter $^{1}$

De acordo com essas discursividades, o papel de cada pessoa na engrenagem da sociedade não dependeria de méritos ou competências, e sim de padrões determinados pela história e que constituem sentidos do "lugar comum" para cada segmento: lugar de idoso, em casa ou no asilo; lugar de mulher, na cozinha; lugar de negro e de nordestino, em funções subalternas.

Causa espanto quando alguém, a exemplo de Regina, ultrapassa as fronteiras do lugar que lhe foi imposto no edifício social. Daí, o dizer de Gentili parece expressar

1 Disponível em < https://Twitter.com/danilogentili/status/730573361273839616>. Acesso em: 20/10/2018.

INTERIN, v. 24, n. 2, jul./dez. 2019. ISSN: 1980-5276.

Marluce Pereira da Silva; Cid Augusto Escossia Rosado. Reflexões foucaultianas sobre o racismo enquanto estratégia de governo de si e dos outros no episódio da "tia do café"..p. 103-118. DOI 10.35168/1980-5276.UTP.interin.2019.Vol24.N2.pp103-118 
sentidos que constituem subjetividades que negam a uma mulher idosa, negra, nordestina, com fala simples e sotaque piauiense, a possibilidade de ocupar a posição de ser parlamentar. No máximo, exercer funções subalternas em espaços sociais.

Tal observação remete a Fanon (2008, p. 36), ao afirmar que o modo de o negro se expressar numa sociedade dominada por brancos racistas define quem ele é ou pode se tornar: "Em um grupo de jovens antilhanos, aquele que se exprime bem, que possui o domínio da língua, é muito temido; é preciso tomar cuidado com ele, é um quasebranco. Na França se diz: falar como um livro. Na Martinica: falar como um branco".

Em outras palavras, ao contrapor-se ao discurso de Regina Sousa em defesa da então presidente Dilma Roussef, Danilo Gentili não critica argumentos ou posições ideológicas. A expressão "você consegue entender o que a senadora Regina Sousa está dizendo", usada por ele parece nos revelar sentidos de zombaria não só da aparência física, mas também da forma de se expressar publicamente, sentidos que parecem apontar que uma negra idosa não poderia ser senadora, apenas a "tia do cafezinho". O que ele diz parece reforçar sentidos da estranheza por encontrar uma mulher cujos traços fenotípicos de negritude numa posição social destinada a pessoas com padrão estético de branco.

A interrogação após o substantivo "senadora" denota, já no início da fala do apresentador, sentidos que atribuem descrédito, a negação da imagem de Regina Sousa. "Tia...", no contexto, remete a pessoa idosa cujo nome é desconhecido por todos. E o lugar do esquecimento vem no complemento “...do café".

O enunciado "Achei que fosse a tia do café", em vez de uma parlamentar federal, é perpassado por práticas discursivas cujos efeitos de sentidos constroem subjetividades estigmatizadas, estereotipadas atribuídas a determinadas atividades laborais, de forma que, ao se ler a postagem no Twitter de Gentili, mesmo sem conhecer a parlamentar muito provavelmente intui-se uma formação imaginária de uma mulher negra e idosa.

Isso porque a expressão utilizada pelo humorista está atravessada por uma memória discursiva cujos sentidos atribuem, desde o séc XVI, aos negros a condição de que são "selvagens, estúpidos, analfabetos" (FANON, 2008, p. 109). É, na perspectiva da genealogia foucaultiana, uma construção vertical em que, mesmo transformado pelas revoluções históricas, a ideia de biopoder permanece latente.

INTERIN, v. 24, n. 2, jul./dez. 2019. ISSN: 1980-5276.

Marluce Pereira da Silva; Cid Augusto Escossia Rosado. Reflexões foucaultianas sobre o racismo enquanto estratégia de governo de si e dos outros no episódio da "tia do café"..p. 103-118. DOI 10.35168/1980-5276.UTP.interin.2019.Vol24.N2.pp103-118 
Se bem-observada, a relação é de poder e de governamentalidade de si e dos outros, semelhante ao de séculos passados. Embora com vocábulos contemporâneos de carga semântica menos explícita, tem-se aí a sociedade binária a qual se refere Foucault (2005): homem/mulher, branco/negro, rico/pobre, nordestino/sudestino.

Não se pode desprezar o "humor" enquanto técnica de exercício do poder nem o meio utilizado para satirizar Regina Sousa, o Twitter, rede social em que Gentili, com suas postagens polêmicas, sob a epígrafe "Desde 1979 estragando tudo e decepcionando pessoas", angariou cerca de 16,4 milhões de seguidores.

O enunciado com sentido humorístico tem apelo, alcança todas as classes sociais, forma opinião, conquista audiência, mas também ódio, especialmente quando envolve política e religião. Basta lembrar o caso do jornal francês Charlie Hebdo, alvo de atentado em 2015, com 12 mortos e cinco feridas, em reação a sátiras ao profeta Maomé.

O humorista é parresiasta, pois, além da crença na verdade sobre seu papel social/profissional, pode sofrer consequências, que vão desde manifestações públicas de repúdio dos seguidores que se identificam e se solidarizam com o alvo do deboche, passando pelo risco das sanções legais, até a ameaça de violência física.

Em suma, a frase de Danilo Gentili é racista, pois evidencia sentidos de práticas discursivas que histórica e socialmente constroem subjetividades de mulheres, negros, idosos e nordestinos e ainda aponta práticas de governamentalidade, porque usa o Twitter para influenciar pessoas a raciocinarem pelo caminho para o qual aponta sua "verdade".

Ainda no campo do governo de si e dos outros, externa discursivamente como inscreve seu papel social e o lugar das "pessoas inferiores”, num exercício de parresía. Indivíduos como a senadora Regina Sousa não podem participar da política, "governar", pois o lugar que lhe cabe no senso comum é o dos "governados".

\section{4 "Eu não tenho cara de senadora"}

Somente por meio da verdade se realiza o bom governo de si e dos outros, ao passo que "somos forçados a produzir a verdade pelo poder que exige essa verdade e

INTERIN, v. 24, n. 2, jul./dez. 2019. ISSN: 1980-5276. 
que necessita dela para funcionar; temos que dizer a verdade, somos coagidos, somos condenados a confessar a verdade ou a encontrá-la" (FOUCAULT, 2005, p. 29).

Confessar a verdade num gesto de parresía, a verdade do seu pertencimento racial, também como estratégia de governo de si e dos outros, para atrair seus iguais, os simpatizantes, contra o adversário racista, foi o que fez Regina Sousa na tribuna do Senado, em resposta a Danilo Gentili. A conferir:

\begin{abstract}
Enquanto eu estava usando da palavra, Danilo Gentili fazia um comentário racista, né, preconceituoso, a meu respeito. Quando eu vim pra tribuna, ele disse: 'Uma sena... senadora? Pensei que era a tia do cafezinho'. Esse moço é... tem feito muitos comentários maldosos, principalmente em relação às mulheres. Ele expressa aí um racismo, né, sem tamanho, porque, pra ele, senadora tem que ter cara de senadora. Eu não tenho cara de senadora, né, com meu cabelo pixaim, né, para ele eu deveria alisar os cabelos, certamente, né. Então, eu não poderia deixar aqui de fazer esse comentário, né, dizer da infelicidade. Felizmente, a população inteira, os seguidores dele... é... reagiram mal ao que ele disse, né, ele se deu muito mal porque foram poucos os a... poucos os seguidores que o apoiaram. Mas eu não vou deixar barato pro Danilo Gentili. Não é questão de... de... indenização, mas eu vou representá-lo em nome das tias do cafezinho, em nome de todas as mulheres que servem cafezinho, eu vou representar... é... contra o senhor Danilo Gentilli. Porque não é a primeira vez que ele faz esses comentários com mulheres" (grifamos).
\end{abstract}

Regina Sousa se utiliza de sua inscrição na posição de sujeito político como técnica de governamentalidade de si e dos outros, primeiro para rotular Gentili de inconsequente, racista e misógino, um "moço" que faz "comentários maldosos" contra mulheres e que se espanta ao ver pela TV uma senadora que não é branca e não tem cabelos lisos.

Depois, em "Eu não tenho cara de senadora, né, com meu cabelo pixaim, né, para ele eu deveria alisar os cabelos, certamente, né", assume a negritude não apenas como gesto de parresía, mas também para buscar apoio entre os interlocutores invisíveis que acompanhavam sua fala pela TV Senado, Rádio Senado e Internet. Não deixa de ser também, como escreveu Fanon (2008, p. 104), uma autorrevelação diante do "olhar do branco", com seu peso opressor. 
Fig. 2 - Foto de Regina Sousa na tribuna do Senado

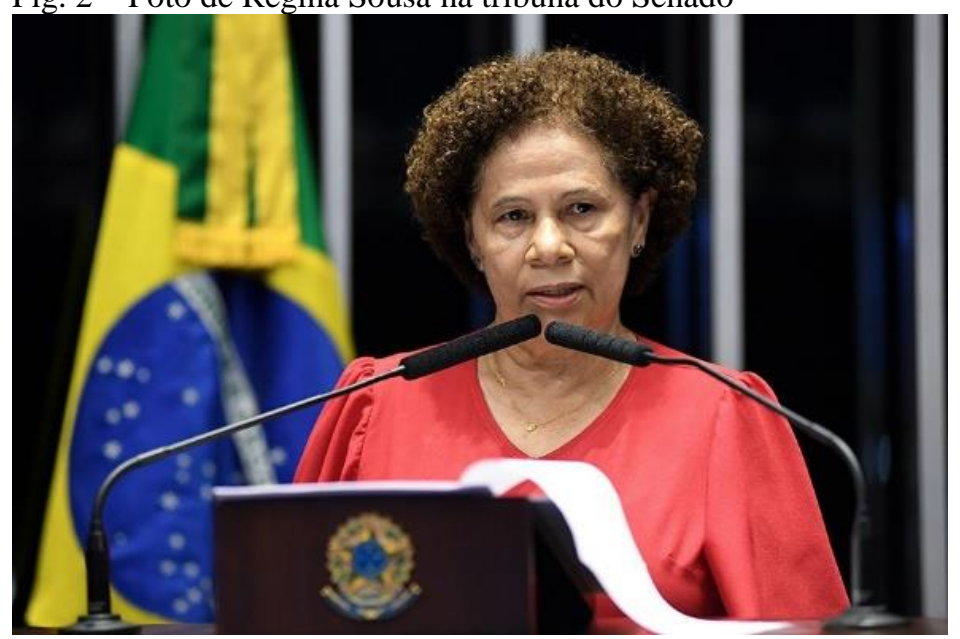

Fonte: Agência Senado/Jefferson Rudy ${ }^{2}$

É como se dissesse, "sim, sou mulher, negra, nordestina, idosa, igual a você, igual à sua mãe, igual à sua avó, igual às tias do café". E por isso, por se considerar a representação de tantas pessoas vítimas do preconceito, por ter uma responsabilidade social com todas elas, pretende processar Danilo Gentili.

Se o apresentador tinha consciência do humor e da polêmica nas redes sociais como estratégias de governo dos outros, para influenciar seguidores e ganhar mais espaço para suas opiniões, o mesmo se pode dizer de Regina Sousa ao encarnar a luta contra o racismo e usar a tribuna do Senado para contra-atacar.

Ela se subjetiva "negra", do "cabelo pixaim", como estratégia voltada ao governo dos outros a partir do governo de si. Quem quebrou paradigmas, deslocandose do lugar social estabelecido há séculos e mantido até hoje, com orgulho de ser quem é, merece ser ouvido, merece ser admirado, merece ser seguido.

Parece irônico, mas no âmbito da governamentalidade, vista por Foucault (2004) como fusão entre técnicas de dominação sobre os outros, a partir das técnicas de si, Gentili e Sousa compartilham estratégias de poder da mesma fonte, a evolução histórica do racismo, trabalhadas na perspectiva social da formação de cada sujeito.

Pode-se afirmar também, agora a partir de Fanon (2008, p. 47), que a senadora, vista com suspeita pelo humorista por estar num dos mais elevados cargos da República, assim como o estudante "negro que cita Montesquieu” é suspeito para o

\footnotetext{
${ }^{2}$ Disponível em < https://www12.senado.leg.br/noticias/materias/2018/10/17/regina-sousa-denunciaas-mortes-por-soterramento-em-armazens-de-graos>. Acesso em: 20/10/2018.
}

INTERIN, v. 24, n. 2, jul./dez. 2019. ISSN: 1980-5276. 
“exército de imbecis", reagiu para quebrar uma visão estereotipada, herança da colonização europeia.

\section{Considerações Finais}

Não há dúvida. O racismo é uma construção sócio-histórica originadora de subjetividades que se constituem discursivamente na linguagem. Por isso, por essa carga na formação dos sujeitos, atitudes racistas nem sempre são percebidas como tal por quem as adota.

O episódio da "tia do café" é um exemplo. A fala de Gentili, que não se declara nem se reconhece racista, reproduz uma espécie de "senso comum" oriundo de práticas segregacionistas, de que os indivíduos têm lugares preestabelecidos na sociedade, de acordo com a cor da pele, a origem regional, a idade.

São a um só tempo amostras da "guerra de raças", quando se contrapõem brasileiros nordestinos e brasileiros do Sul; assim como do biopoder, na perspectiva de que uma mulher, ainda por cima negra, não pode ser senadora, porque seu lugar é na copa, servindo aos senadores.

"Pensei que era a tia do café" não é diferente de "negro de alma branca", "é pretinho, mas é arrumadinho", "negro de traços finos", expressões cotidianas utilizadas por pessoas brancas e negras, sem a percepção da carga cultural que se desvela nas discursividades que atravessam tais expressões ajudam a construir sentidos quanto ao lugar de cada um. A análise do embate entre Danilo Gentili e Regina Sousa revela também como o racismo pode servir enquanto técnica de governabilidade de si e dos outros. Ambos, o humorista e a senadora, usam tecnologias de si na forma de discursividades tanto para contra-atacarem-se quanto para arregimentar adeptos às suas causas.

Do mesmo modo que a polarização entre candidatos a determinado posto isolaos dos demais, tornando-os o centro das atenções, verifica-se na simples polarização dos discursos racista e antirracista objetos deste estudo, a emergência de estratagemas de poder e de efeitos de governabilidade.

As repetidas manifestações de Gentili depreciativas aos negros - king-kong, tia do café - não são apenas racismo travestido de humor, são uma fórmula de aumentar

INTERIN, v. 24, n. 2, jul./dez. 2019. ISSN: 1980-5276.

Marluce Pereira da Silva; Cid Augusto Escossia Rosado. Reflexões foucaultianas sobre o racismo enquanto estratégia de governo de si e dos outros no episódio da "tia do café"..p. 103-118. DOI 10.35168/1980-5276.UTP.interin.2019.Vol24.N2.pp103-118 
a influência de suas redes sociais e projetar a própria imagem por meio da polêmica e, como essa tática de poder, exercer o "governo" dos outros.

Na perspectiva da governança, entrando pelo viés da parresía, os efeitos de sentidos do dizer de Gentili não são inocentes ou espontâneos. Suas verdades são calculadas e as reações, de apoio ou repúdio, servem-lhe igualmente aos propósitos de se manter em evidência, ampliar a influência, abrir espaço da mídia e angariar patrocinadores.

A fala de Regina em contraponto à de Gentili também não é ingênua. Segue idênticas técnicas de poder com emprego da mídia e de governabilidade. De governo de si, o cuidado de si que a levou ao Congresso; e de governo dos outros, com verdades para atrair adeptos à sua "indignação" e provocar reações dessas pessoas ao contendor.

Conclui-se, assim, que ambos são parresisastas no sentido foucaultiano, no sentido de dizer a verdade, a verdade de cada um, conscientes das reações negativas, dos riscos pessoais de serem insultados nas redes sociais, por exemplo, num tempo em que qualquer pessoa com acesso à Internet pode promover julgamentos públicos.

Os dois encarnaram o dizer-a-verdade do discurso político, disseram tudo, empunharam cada qual sua "verdade" e falaram com franqueza, sem temer o interlocutor direto ou o interlocutor invisível alcançado pelos veículos de comunicação empregados no embate (rede social, TV e rádio).

O humorista, não obstante o caráter questionável de suas críticas, lançando mão do direito democrático de usar da palavra contra uma representante do povo; e a senadora ao defender a participação das pessoas na vida política nacional independentemente de questões raciais, etárias e econômicas.

Todo movimento de governamentalidade, de governo de si, de governo dos outros, de parresía, ganha forma na linguagem, através da linguagem. Por isso, o discurso racista ou antirracista objetificado neste artigo é historicamente constituído nas relações sociais e consolidado ou transformado ao longo do tempo.

O que se tem hoje por racismo são, portanto, fragmentos de historicidades absorvidos pela ordem do discurso vigente, contemporânea, que certamente sofrerá modificações ao sabor das convergências e conflitos sociais, e com maior velocidade e campos de influência, dada a evolução dos meios de comunicação.

INTERIN, v. 24, n. 2, jul./dez. 2019. ISSN: 1980-5276. 


\section{REFERÊNCIAS}

FANON, Frantz. Pele negra, máscaras brancas. Salvador: EDUFBA, 2008.

FOUCALT, Michel. Tecnologias de si, 1982. Verve, nº 6: 321-360, 2004. . Em defesa da sociedade. São Paulo: Martins Fontes, 2005.

Microfísica do poder. Rio de Janeiro: Graal, 2007.

. A hermenêutica do sujeito. São Paulo: WMF Martins Santos, 2011.

O governo de si e dos outros. São Paulo: WMF Martins Santos, 2013.

A coragem da verdade. São Paulo: WMF Martins Santos, 2014.

Recebido em: 29.10.2018

Aceito em: 13.06.2019 